\title{
An Investigation of the Open Innovation Landscape of Fish and Seafood Processing Industry in United Kingdom
}

\section{A. M. De Silva ${ }^{1}$ and Trond Bjorndal ${ }^{2}$}

${ }^{1}$ Department of Agribusiness Management, Faculty of Agricultural Sciences, Sabaragamuwa University of Sri Lanka, P.O. Box 02, Belihuloya, Sri Lanka.desilva.achini@yahoo.co.uk

${ }^{2}$ Centre for the Economics and Management of Aquatic Resources (CEMARE), Portsmouth Business School, University of Portsmouth, St. George's Building, 141, High Street, Portsmouth, Po1 2HY, United Kingdom.Trond.Bjorndal@port.ac.uk

\begin{abstract}
Co-creation or open innovation so far been studied mainly on product and process development in high-tech manufacturing industries. This paper attempts to investigate the involvement of external sources on fishery resource conservation in the UK. Drawing on a data collected from 32 small, medium and large fish and seafood processors and retail chains, we have investigated the positive contribution of external sources on resource conservation measures. Large processors and retail chains manage bigger networks and maintained close links with external crowds compared to small and medium. Creation and implementation of conservation measures through cocreation is common strategic tool and top gainers of the process were large processors and retail chains. Winning respect, establish trust among partners, build market image, value creation and brand promotion were the key perceived benefits.
\end{abstract}

Keywords: crowd sourcing, fish and seafood processing, resources conservation

\section{Introduction}

Fishery is a common property with open access nature. Conservation efforts needs to join the hands of all stakeholders and based on external knowledge. Collaborative efforts are proliferating for many reasons and they have provided an impetus for the growth of co-creative initiatives (Wondolleck and Yaffee, 2000). Fish and seafood processing industry depends heavily on natural resources sourced globally and involved many external stakeholders and their involvement is essential to establish proper tools. Throughout the world, successfully managed fisheries use co-management efforts through active participation of all stakeholders. Moreover, being common property, owned by different users necessarily need to open the conservation efforts to 
get collaborative ideas to develop sustainable resource management efforts. Some collaborative efforts have developed in response to the problems evident in resources management in recent decades, such as MSC labelling, Dolphin safe Tuna labelling, etc.

The authors were designed the current research to investigate the involvement of open innovation activities on resource conservation efforts in the fish and seafood processing industry of the United Kingdom. Further, study focused to identify the external crowds and their contribution in conservation efforts and measure the importance of both internal and external sources on the development of conservation strategies and its implementation.

\section{Fish and seafood processing industry in the United Kingdom}

Fish and seafood marketing in the UK is progressing steadily (Sea Fish Industry Authority, 2009). Demand in the UK has been maintained positively during the recent recessionary period. The catching sector is not just restrained by limits on what they can catch, but also face restrictions on the amount of the time they can spent at sea (Seafood Scotland, 2010). This has direct impact on the volume of deliveries to the market and large scale processors are depending on imported raw materials. Moreover, processors are also having difficulties in maintaining a steady flow of products. Therefore, all parties need to work together to manage profitable businesses. Fishermen and processors are interdependent each on each other for their future.

Fish and seafood industry of United Kingdom composed of small number of large processors with distributed subsidiaries of them and large number of small-scale processors scattered around the country (SEAFISH, 2009). Furthermore, industry is concentrated more in Humberside and Grampian regions followed by South midlands, Wales and North England. Scotland is facilitating farming and processing of Salmon mainly. Industry depends on raw material supplies of both local and imports.

Sea fish industry survey (2009) highlighted that imports showing increasing trends while landings of both demersal and pelagic species decreasing in the UK. Primary processors were closely linked with producers and their raw material comes through auctions and direct contacts with the fishermen and fish farmers. Large scale processors mainly depend on high volumes of imported raw materials while medium scale depends on mainly local and some imported materials. Quality concerns depend on the scale of processors where small and medium processors stick to the government (Food Standards agency) regulations. Larger processors dealing with international markets and they concern more on quality standards and labelling procedures and consumer appeals. 
Furthermore, largest customer group for the industry as a whole is retail chains which attract $57 \%$ of sales (70\% of large processors). Therefore, retail chains and individual retailers have high impact on the industry. Retailers place high priority on environmental and resources conservation efforts, and sustainability concerns born by consumer lobbying. Sea Fish Industry survey (2009) emphasises that energy costs, raw material costs and environmental issues are key concerns of the large scale processors and retail chains. Small and medium scale processors do not perceive themselves to be affected by environmental issues while for others environmental issues have a big impact on the way they operate. Many processors seem unaware of the environmental issues affecting their business. Seventy five percent of the large processors and $50 \%$ of the medium sized processors required to show customers an environmental policy in comparison with only $25 \%$ of small processors (Sea Fish Industry Authority, 2009). Especially, large processors are dealing mainly with the retail chains and they concern much more on resource conservation efforts.

\section{Open innovation: A new window for resource conservation}

The basic premise of open innovation is opening up the innovation process (Huizingh, 2011). Open innovation has many faces and comes in different forms regardless of the industry. Knowledge inflows and outflows is popularly used concept of open innovation. Lichtenthaler and Lichtenthaler (2009) distinguish between three knowledge processes (Knowledge exploration, retention and exploitation) that can be performed either internally or externally.

Fish and seafood value chains, beginning from fisher to final consumer depends on resource availability. Moreover, nature of the common property invites all stakeholders to consume together as well as conserve together. Participatory conservation efforts of the all stakeholders, including fishers, suppliers, processors, wholesalers, retailers, traders, distributors, consumers, governments, non-governmental organizations (NGOs), scientists, etc. will bring fruitful results.

Today, collaboration with other people to understand the similar needs, ideas and thoughts is key to success in the global market place (Gulshan, 2011). The current innovation landscape has changed and collaborative efforts are common in most industries. Due to labour mobility, abundant venture capital and widely dispersed knowledge across multiple public and private organizations, enterprises can no longer afford to innovate on their own, but rather need to engage in alternative innovation practices (Vrande et al., 2009).

External crowds as well as internal crowds can be involved in innovation processes in multiple ways, for an example taking up their suggestions, 
exempting them to take initiatives beyond organization boundaries or introducing suggestion schemes such as idea boxes and internal competitions (Van Dijk and Van den Ende, 2002). External networking is another important dimension which is consistently associated with open innovation (Chesbrough et al., 2006). It includes all activities to acquire and maintain connections with external sources of social capital, including individuals and organizations (Van de Vrande et al., 2009).

Especially, open innovation theorists recognize that customer involvement is one important alternative to inform internal innovation processes (Gasman, 2006). Fish and seafood value chains are organized and dedicated to cater for the global consumer demands. This provides starting point to our discussion on conservation of fish and fishery resources through global consumer commitments. Firms may benefit from their customers' ideas and innovations by proactive market research, providing tools to experiment with and/or develop products similar to ours that are currently offered or by producing products based on the designs of customers and evaluating what may be learned from generous product development (Van de Vrande et al., 2009).

External knowledge is known to be distributed our various actors (Tether, 2002) and accessible through a multitude of channels (Coombs et al., 2003; Howells et al., 2003; Acha and Cusmano, 2005). In the era of open innovation (Chesbrough, 2003) the need to access external "public" knowledge has gained a lot of importance (Lichtenthaler, 2008). In this context, firms are part of an environment that is characterized by distributed knowledge and the innovation process is distributed across a number of actors in the innovation system (Tether, 2002; Acha and Cusmano, 2005; Spithoven et al., 2010).

Article composed of four sections. First section focuses on an introduction which composed of overview of the fish and seafood processing industry in the United Kingdom and the role of open innovation in fishery resource conservation. Section two explains the research methodology. Final two sections discuss the findings of the study and derived conclusions.

Conceptual framework (figure 01) of the study was based on the previous research as well as the principals of open innovation theory. Company resources were divided into two sections, where physical, financial, human, social and natural capital belongs to the company considered as internal resources and external crowds and their resource base considered as external resources. Conservation efforts developed through collaboration designed to achieve the sustainability of fish and sea food processing industry. 


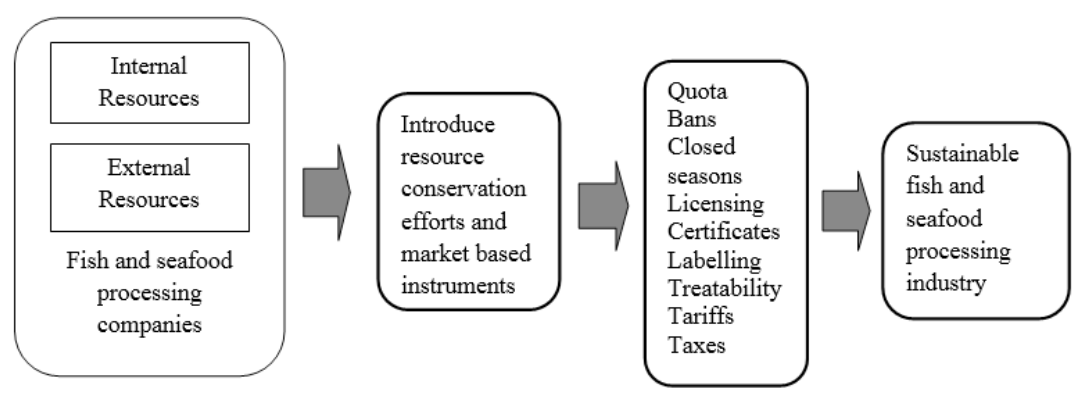

Figure 01: conceptual frame work

\section{Methodology}

Study was conducted during the winter 2012 and primary data were obtained from the fish and seafood processors of the UK. Research sample composed of processors based on Grampian, Humberside, Scotland, Wales and South West regions of the UK. Moreover, study considered only the processors who materially convert the fish and seafood into finish products and large scale retailers who carried out own processing. Processors were divided into 3 main categories, small (1-25 employees), medium (26-100) and large (>100 employees) based on the Sea Fish Industry authority classification.

Authors were employed structured questionnaires and in-depth interviews as their key data collection tools. Structured questionnaire composed of two main sections. First section was designed to collect the brief information of the processing facility and second part was directed to identify and measure their involvement in environmental and fishery resource conservation through open innovation practices. Questions were designed to identify the external crowds and their intervention on environmental and fishery resource conservation efforts. Four point rating scale were used to measure the degree of importance of both internal and external sources on open innovation efforts on fishery resource conservation.

Questionnaires were e-mailed to around 76 small, medium and large processors and retail chains managing own processing facilities and 32 were returned (12 small, 6 medium, 8 large processors and 6 retail chains). Telephone survey was conducted along with the questionnaires. Processors who have returned the e-mailed questionnaire were invited to join the telephone survey and discussions were held with prior arrangements. Further, industry stakeholders and their representatives were interviewed for the purpose of institutional analysis. Comparative institutional analysis (Herrera et al., 2005) was employed which aimed to identify the structure of the institutions, efficiency of institutions on resource implementation of conservation strategies, institutional choice on 
resource conservation measures and institutional changes based on external environment. Open innovation landscape was developed using the results of the institutional analysis (see figure 2).

Of the sample processing establishments showed different structures where own R\&D department, other departments or divisions within the firm and its subsidiaries were considered as internal sources of open innovation landscape. External sources of the processors were categorized into 3, value chain members, institutional sources and others. Value chain sources composed of producers (fishermen and fish farmers), suppliers and traders, consumers, competitors, logistic providers and distributors, business consultants and market research organizations. Universities, government and private research institutions, NGOs and other governmental institutions facilitate fisheries industry were the members of external institutional sources. Especial concern has paid on NGOs where they were playing important role behind the resource conservation and sustainability issues. Trade fairs and exhibitions, professional meetings and conferences, published sources and industry associations were included as other external sources.

\section{Results and discussion}

Study has designed to identify the crowd sourcing partners and the open innovation landscape of the fish and seafood processing industry of the United Kingdom. Study reveals that open innovation platform composed of 3 phases, idea generation, and development and marketing (figure 4). Results of the institutional analysis were used to develop the existing open innovation landscape for the industry (figure 2). Institutional analysis highlighted that value chain members were maintaining closer ties with the processors and they were playing critical role in identifying and implementing conservation measures beyond boundaries. Other external sources were maintained varied relationships with processors but their involvement was influential on conservation measures.

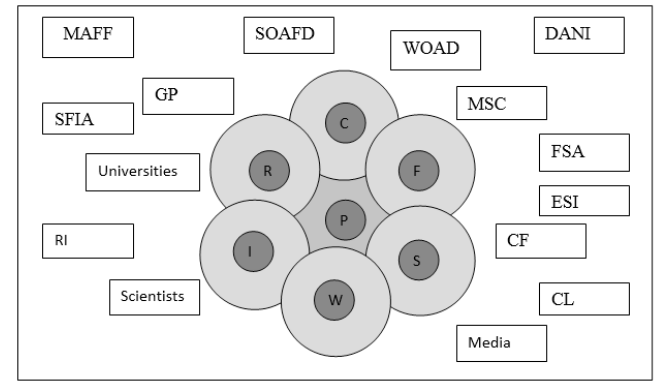

Figure 02: open innovation environment

( P- Primary and Secondary processors; C- Consumers; F- Fishermen; S-Suppliers and Traders; W-Wholesalers; E-Exporters; R-Retailers and Retail chains; MAFF-Ministry of Agriculture Food and 
Fisheries; SOAFD- Scottish Office Agriculture Environment and Fisheries Department; WOAD- Welsh Office Agriculture Development; DANI- Department of Agriculture for Northern Ireland; MSC- Marine Stewardship Council; RI-Research Institutions: ESI- Earth Science Institute; SFIA- Sea Fish Industry Authority; FSA-Food Standards Agency; GP- Green Peace; CL- Consumer Lobbies; CF- Consultancy Firms )

\section{Open innovation process: 1. Idea generation}

This phase begins with searching both internal and external ideas on product and process development. Conservation efforts attract much attention due to heavy dependency on environment for sourcing raw materials and some of the consumer segments places high demand on responsible products and processes. Of the sample five groups were identified as major sources providing ideas on product attributes as well as responsible production processes. Fish and seafood producers were playing great role in responsible fish and seafood production and which enables processors to claim for specific labelling and certifications. Popular examples in international market were MSC certification, organic/eco labels, Dolphin safe Tuna labelling, Friends of Sea, etc. Institutional involvement was considerable compared to consumers (see figure 03).

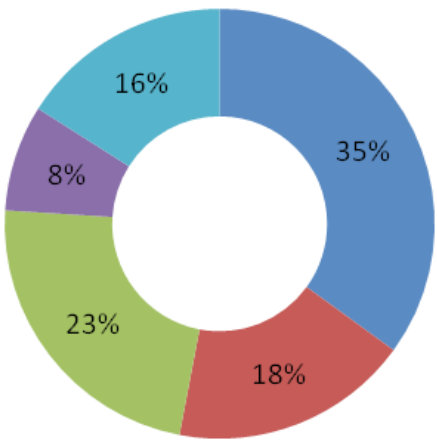

Fishermen, fish farmers \& producer organizations

- Universities \& research institutions

NGOS

Consumers

a Government

Figure 03: Idea pool and contributions of stakeholder groups

\section{Responsible product development}

Internal crowds, $R \& D$ labs and internal employees were playing important role in responsible product development phase where fair contribution of the producers was critical. External crowds intervene more on responsible product development of fast moving consumer goods category including value added forms of fish and seafood products. Furthermore, intervention of external crowds became crucial when sourcing raw materials globally. Fishing grounds across nations and oceans were maintaining varied management practices as 
well as believes attitudes on resource conservation. Ideas of both producers and processors were involved in finalize the species, fishing ground, fishing methods based on conservation measures i.e. MSC certified fishing, ethical labour, IUU fishing, carbon emissions, and governance. Positive contribution of both internal and external crowds observed during product and process development phase. Product development phase accommodates the ideas of external crowds through market surveys, internships, competitions, votings, etc. Spin offs of large scale processors and retail chains brings more beneficial inputs into the process while retailer specifications and market segments requirements ask for mandatory changes.

\section{Marketing}

Final stage, marketing is critical to any manufacturer and growing concerns on fishery resource conservation and environmental issues broaden the scope. Resource integration, both internal and external was mutually beneficial combination commercializing value added fishery products. Marketing facilitates to broadcast the open innovation strategy and to enhance the global awareness on concepts. Resource conservation efforts and environmental concerns act as popular marketing strategy and play a great role in communicating product ideas to target segments.

External crowd sourcing facilitates to identify the new market opportunities such as enter into new market segments (consumer segments on health, environment, resource, regulation, labelling etc. concern segments), emerging markets (South east Asia, Latin America, Russia, etc.). Collaborative marketing strategies led to promote both brand and conservation efforts. On the other hand, marketing campaigns act as promising strategy to promote conservation measures and sourcing of responsible products. Figure 04 presents the open innovation framework for responsible fish and seafood production.

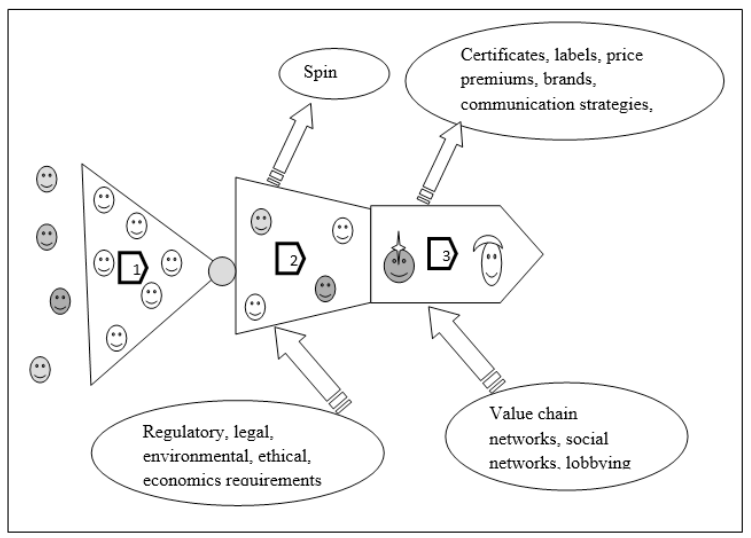

Figure 04: Open innovation framework for fisheries: responsible fish and seafood production 
Sample survey has identified the network sizes of the various processors and their level of open innovation strategies on fishery resource conservation. Of the sample small scale processors were maintain open innovation networks with few partners whereas large scale processors and retail chains maintain bigger networks (see figure 05). Further, levels of open innovation strategies were parallel with the size of networks.

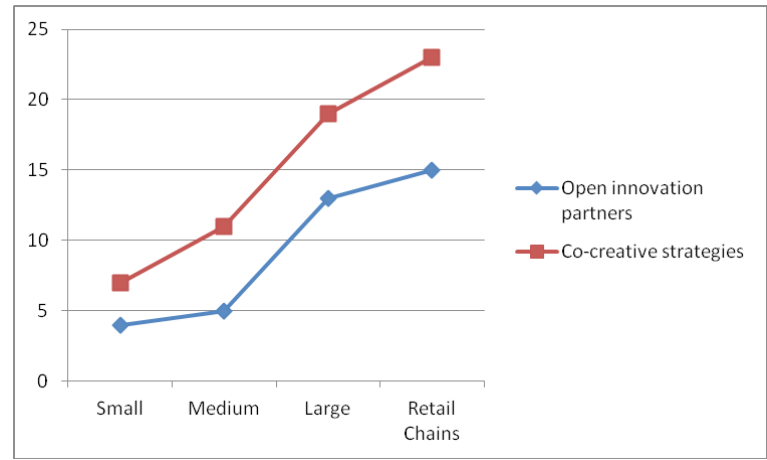

Figure 05: Open innovation partners and strategies of various processors Source: field survey, winter 2012.

\section{Open innovation process and involvement of the internal sources}

Authors focused to identify the intervention of both internal and external sources on open innovation process. First measured the involvement of internal sources where internal sources were categorised into 3 groups, own R\&D department, other departments of the company and subsidiaries of the company. Results revealed that large scale processors and retail chains were considered their internal sources as important part of the open innovation process. But small and medium scale processors showed contrasting picture where own R\&D department was considered as most important group (figure 06). In general, small and medium processors operated as individual units with limited number of employees and departments or sections were absent in their business structure.

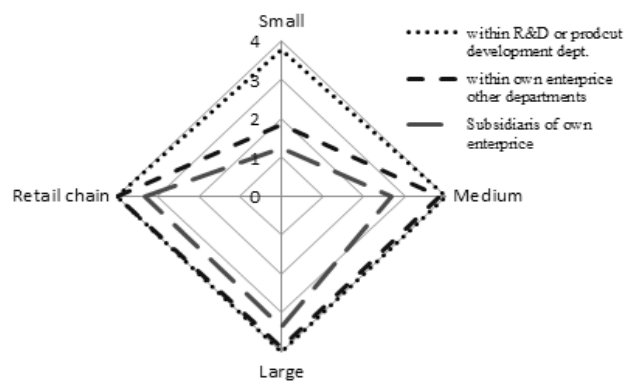

Figure 06: Evaluation of internal sources on resource conservation 
Next focus of the study was to identify the involvement of value chain members on the open innovation process. Both large processors and retail chains were the members of diverse, complex and longer value chins compared to medium and small scale processors. Large processors and retail chains were behaving similar way compared to small and medium scale processors (see figure 07). Fish producers, suppliers, consumers and business consultants were the highly important value chains resources for large processors and retail chains while logistic providers were not considered as important for them. All value chain sources were considered less important for medium processors while producers were the highly important source for small scale processors.

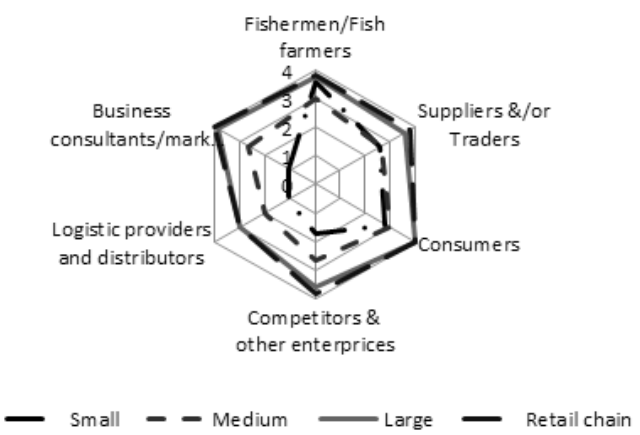

Figure 07: Evaluation of value chain sources on resource conservation

Next attempt was to identify the involvement of external institutional sources on open innovation process. NGOs were considered as highly important institutional source for both large processors and retail chains while they were highly dedicated on development and implementing conservation measures (see figure 08). Government institutions were the least important compared to others. None of the institutional sources were important for both medium and small processors.

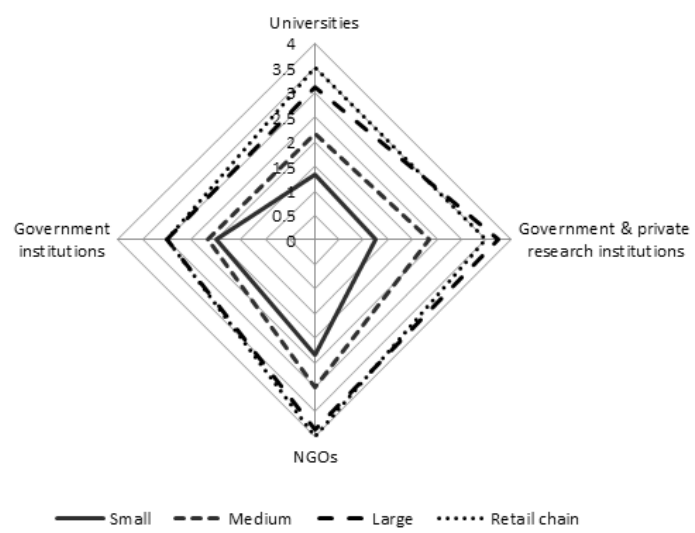

Figure 08: Evaluation of Institutional sources on resource conservation 
Final concern was focused to identify the involvement of other sources for information, trade fairs and exhibitions, professional meetings and conferences, published information and industry associations on open innovation process. Large processors and retail chains were closely linked with industry associations and their participation were high in trade fairs, exhibitions and professional conferences compared to medium and small processors. Of the sample both large processors and retail chains highlighted that other sources were important for knowledge, awareness and market information (see figure 09).

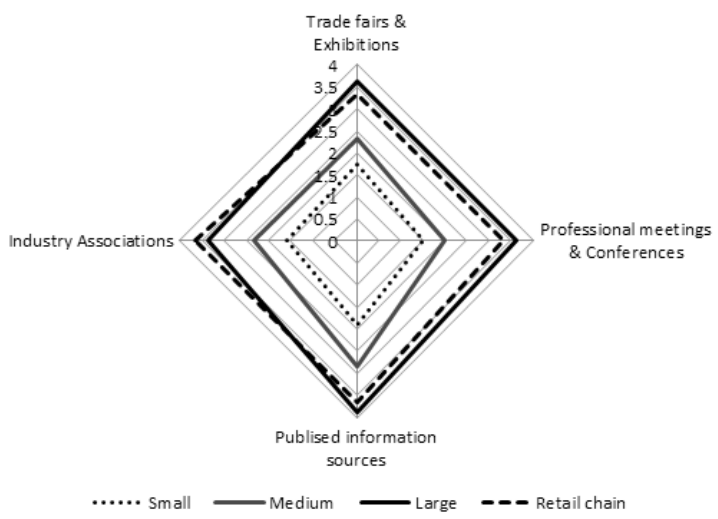

Figure 09: Evaluation of other sources on resource conservation

Key considerations of the study were to identify the benefits of open innovation process on resource conservation (see figure 10). Winning respect, establish trust among partners, build market image, value creation and brand promotion were identified as positive returns while similar pattern was observed for both large processors and retail chains. Of the sample, both small and medium processors were not producing branded products and they were more engage on direct marketing. Therefore establish trust among partners were the positive return for them.

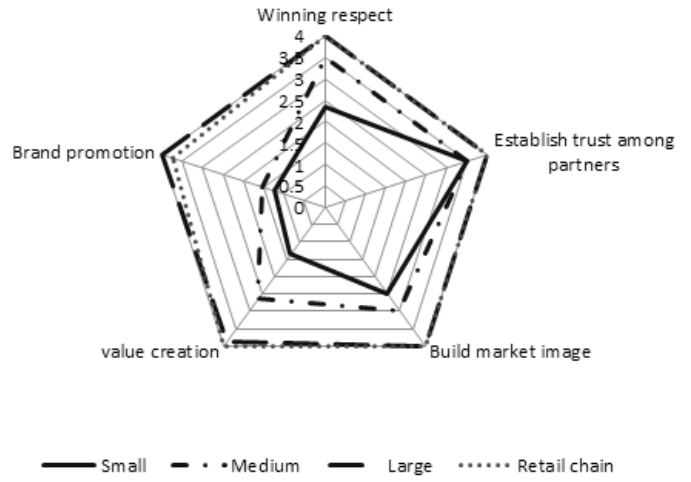

Figure 10: Benefits of engaging co-creation activities on resource conservation 


\section{Conclusions}

The focus in this article was to investigate the open innovation landscape of fish and seafood processing industry of the United Kingdom. Further, the study designed to identify the open innovation process, its stake holders and their involvement on fishery resource conservation efforts and the returns of the process.

Open innovation landscape of the fish and seafood processing industry of the United Kingdom composed internal and external sources. Value chain members, governmental institutions, NGOs, were mainly identified as external sources. Open innovation process composed of three stages, idea generation, product development and marketing. Processors were receiving ideas on resource conservation from both internal and external sources. Idea filtering process occurred in phase one and then selected ideas enter into phase two, product development. Developed product concepts entered into final phase marketing. In general, most of the innovative fishery resource conservation initiatives were born through the collaborative process. Both internal and external sources were engaged into foster the creative partnerships that have made a difference in market place.

Study has identified the open innovation partners and their size of the network of various fish and seafood processors. Large scale processors and retail chains were maintaining larger networks compared to small and medium scale processors. Further, open innovation strategies were parallel with the size of the network and larger scale processors and retail chains were strengthen with large number of strategies compared to rest in the sample.

Own R\&D department has considered as most vital internal source for all processors. Large scale processors and retail chains were recognized other internal sources were important to them and small and medium scale processors were showed contrasting behaviour. Large scale processors and retail chains behave similarly with value chain members on open innovation process while small and medium scale processors were consider more on the involvement of producers. Open innovation in fishery resource conservation help to establish networks among value chain members, assist in development of rich pools of knowledge and skills that draw from value chain and other sources, bridge the gap between consumers and processors, lead to generate creative ideas and approaches, help to improve market intelligence and can create a dialogue on sustainability of fishery resources and individual responsibility.

NGOs were recognised as critically important segment involving in the process where large scale and retail chains maintain closer relationships with them. External institutions were less involved with the process of small and 
medium scale processors. Governmental institutions were playing key role as a legislator facilitator. Their way of collaboration based on establishment of rules, regulations and policies which guide the better industry practise.

Moreover, participation of trade fairs and exhibitions, industry associations, professional meetings, conferences, and industry associations were considered as important to the open innovation process of the large scale processors and retail chains. Small and medium scale processors were not recognised the benefits of others sources.

Large processors and retail chains were the top gainers of co-creation activities on fishery resource conservation. Winning respect, establishes trust among partners, build market image, value creation and brand promotion were the perceived benefits to them. Establish trust among partners were the key single benefit received by both medium and small processors.

\section{References}

Acha V., Cusmano L., 2005. Governance and co-ordination of distributed innovation processes: patterns of R\&D cooperation in the up stream petroleum industry, Economics of innovation and New Technology Vol14 pp1-21. http://dx.doi.org/10.1080/1043859042000228651

Chesbrough H., Vanhaverbeke W., and Weat J., 2006. Open innovation: Researching a New Paradigm, Oxford University Press, London

Coombs R., Harvey M., and Tether B., 2003. Analysing distributed process of provision and innovation, Industrial and corporate change, Vol.12 pp 1125-1155. http://dx.doi.org/10.1093/icc/12.6.1125

Gassmann, O., 2006. Opening up the innovation process: towards an agenda, R\&D management, Vol. 36 (3) pp223-228. http://dx.doi.org/10.1111/ j.1467-9310.2006.00437.x

Gulshan, S. S., 2011. Innovation Management: Reaping the benefits of open platforms by assimilating internal and external innovations, ProcediaSocial and Behavioural Sciences Vol. 25 pp 46-53. http://dx.doi. org/10.1016/j.sbspro.2011.10.527

Herrerra P.A., Huylenbrocek G., and R.L. Espinel. (2005). A generic four step methodology for institutional analysis of governance structures. 99 $9^{\text {th }}$ seminar of the European Association of Agricultural Economists, Copenhagen, Denmark. 
Howells J., James A., Malik K., 2003. The sourcing of technological knowledge: distributed innovation processes and dynamic change, R\&D management Vol. 33 pp 395-409. http://dx.doi.org/10.1111/14679310.00306

Huizingh, E.R.R.E., 2011. Open innovation: stages of the art and future perceptions, Technovation, Vol.31 pp2-9. http://dx.doi.org/10.1016/j. technovation.2010.10.002

Lichtenthaler, U., Lichtenthaler E., 2009. A capability based framework for open innovation: complementing absorptive capacity, Journal of management studies, Vol. 46 (8) pp1315-1338. http://dx.doi.org/10.1111/ j.1467-6486.2009.00854.x

Lichtenthaler U., 2008. Integrated road maps for open innovation, Research and Technology Management, may-June, pp 45-48

Seafood Scotland, 2010. Scottish Seafood Industry Update-2010, Seafood Scotland, Accessed 12 $12^{\text {th }}$ January 2012. www.seafoodscotland.org/en/ news/319-scottish-seafood-industry-update-july-2010.html

Sea Fish Industry Authority. 2009. 2008 survey of the UK seafood processing industry, Sea Fish Industry Authority, Seafish Economics, 18, Logie Mill, Logie Green Road, Edinburgh, EH7 4HS, United Kingdom. Accessed $15^{\text {th }}$ November 2011. www.seafish.org/media/Publications/SR608_2008_ Survey_of_the_UK_Seafood_Processing_Industry.pdf

Spithoven A., Clarysse B. and knockaert M., 2010. Building absorptive capacity to organize inbound open innovation in traditional industries, Technovation, Vol. 30 pp 130-141. http://dx.doi.org/10.1016/j. technovation.2009.08.004

Tether B., 2002. Who co-operates for innovation and why: An empirical analysis, resource Policy Vol. 31 pp 947-967

Van Dijk C., and Van den Ende J., 2002. Suggestion systems: transferring employee creativity into practical ideas, R\&D Management 32, pp387395. http://dx.doi.org/10.1111/1467-9310.00270

Vrande Vareska van de, Jong J.P.J. de, Vanhaverbeke W., Rochemont M. De, 2009. Open innovation in SMEs: Trends, motives and management challenges, Technovation, Vol. 29 pp423-437 
Valatin Gregory, 1999. UK fisheries management institutions and mechanisms: An Aidememo, The $\mathrm{xi}^{\mathrm{th}}$ annual conference of the European association of Fisheries Economists, Dublin $6^{\text {th }}-10^{\text {th }}$ April 1999. Accessed $5^{\text {th }}$ January 2012. www.eafe-fish.org/conferences/99Dublin

Wondolleck Julia M. and Yaffee Steven L., 2000. Making collaborative work: Lessons from Innovation in Natural Resource Management, Island Press, Suite 300,1718, Connectocut Ave., NW Washington DC 20009 pp 3-27. 